\title{
Software Industry Integration Process of Informatization and Industrialization
}

\author{
Lianxing MIN ${ }^{1, a}$, Jianqiong WANG ${ }^{1, b}$ and Qian $L_{U} O^{2, c}$ \\ ${ }^{1}$ School of Economics and Management, Southwest Jiao-tong University, Chengdu, 610031, China, \\ ${ }^{2}$ Finance Bureau of Chengdu, Sichuan, Chengdu, 610000, China \\ amd3318@163.com, bqiongsi007@126.com, ${ }^{\mathrm{a}} 122633447 @ q q . c o m$
}

Keywords: Software Industry, Integration of Informatization and Industrialization, Input-Output Analysis, China

\begin{abstract}
Based on the national input-output data 2007 in China, this paper analyses the economic effects of software industry in the integration process of informatization and industrialization using the method of input-output analysis. Compared to the information manufacturing industry, software industry has the different industries linkage structure and its development relies on itself more. The spread effects analysis shows the two industries have the strong effects on promoting other manufacture industries' development.
\end{abstract}

\section{Introduction}

Industrialization and informatization are two important characteristics of development of modern society. The developed countries, just as US, started the process of informatization based on the high industrialization level. But in China the process of informatization and industrialization are synchronization in the time. The integration development of informatization and industrialization (IDII) had become the new development mode chosen by China in the trend of industrial convergence. The new mode will provide a better opportunity to China to narrow the gap of industrialization and informatization with western countries. Studies in theory indicated that the development of information industry can promote technology and management innovation and improve productivity of traditional industries, and feedback by an important market foundation. Liu and Feng (2014) evaluated the equilibrium degree of IDII in different regions in China [1]. Xu and Sun (2009) pointed the significant positive correlation existed in the level of IDII and the performance of manufacturing industries [2]. In the perspective of the traditional three industrial structures, the sectors of information industry can be classified into the information manufacture industry and information service industry. The different sectors may play a different role in the process of IDII, but the differences were ignored in the literature. In the context of servitization of manufacturing, manufacture industries' reliance on information services as the intermediate input is gradually strengthening [3]. The software industry is the core of information service industry and considered to be the catalysis of IDII [4], but in the empirical literature this role hasn't been supported.

There are three major methods in the economic impact analysis: econometric method [5], input-output (IO) analysis [6] and the computable general equilibrium (CGE) model [7]. Econometric method can simply acknowledge whether the correlation or causal relationship exists among the different industries by fitting econometric model. But it's difficult to characterize the difference of the impacts on the different industrial sectors with the total amount data. The IO analysis can capture various inter-linkages between sectors with the exchange of production among the sectors. The CGE method can also establish interrelationship between different economic sectors, but it focused more on the effect of policy reform and had more stringent constraint which brings the difficulty of obtaining data. Compared with other methodologies, the IO analysis is the most proper one to capture production-inducing effect and value-added effect, so this paper chose to use it. 


\section{Methodology and data}

Input-Output Analysis. The methodology of this paper is static IO analysis which is proposed by Leontief in the 1930s [8]. It is useful in analyzing the economic interrelationship among sectors of an economy by fitting an IO model, but only reliable in the short to medium term. See Tang et al. (2011) for detailed description of the method in the literature [9].

Sample and Data. The sample data in this paper is collected from the national IO table 2007 in China, which contains 135 sectors. We rearranged a new IO table contained 85 sectors by deleting the non-information or non-manufacture industries data and merging the related industries data to construct the information manufacture and software industry like $\mathrm{Xu}(2010)$ [6].

\section{Empirical Results}

Economic effects of software industry based on input-output analysis include three parts of correlation effect, industrial property and spread effect.

Correlation effect. Correlation effects include consumption and distribution effects. Direct effects can be measured by direct consumption coefficient and total consumption coefficient. Direct consumption coefficient is used to describe the direct consumption on another sector's productions for one unit production of the specific industry, and it rises with the consumption increasing. Total consumption coefficient describes the total consumption including the direct consumption and the induce consumption. So the indirect effect can be measured by the difference between the total consumption coefficient and direct consumption coefficient. Distribution effect used to describe the production of the specific industry is consumed by another sector. It also has the direct coefficient and total coefficient, just like the consumption effect. Although there won't to show the whole correlation coefficients for the length limit of this paper, we also can find that the software industry has highest correlation of information manufacture industry in consumption and distribution effect, and the following is itself. Meanwhile, the information manufacture industry has an extensive correlation with other manufacture industries.

Industrial Property Analysis. Industrial property can be described by intermediate input rate (IIR) and intermediate demand rate (IDR).The IIR is the ratio of the intermediate input from other industries to the total, it's the sum of the direct consumption coefficients in fact. While the IDR is the ratio of production used to other industries to the total, it's also the sum of the direct distribution coefficients. Both of them are more than zero and less than one. We find that the information manufacture industry has a high IIR (0.82) and its IDR (0.47) is in medium level, but the two rates of software industry, IIR (0.29) and IDR (0.23), are observably lower than the information manufacture industry.

We can construct a graphic of four quadrants, with IIR as the transverse axis and IDR as the longitudinal axis. As the Fig 1 showed that the software industry is in the zone IV. It reveals that the software industry has the low consumption on other sectors' production and its production also be few consumed by other sectors. So it means the most of its production is used to final consumption and the less consumption of other sectors' production. Meanwhile the information manufacture industry is in the zone III. Its production is also used to final consumption, but has the high consumption of other sectors' production. We can conclude that the development of software industry has high reliance on itself and low contribution to other industries, while the development of information manufacture industry has higher contribution to other industries than it. 


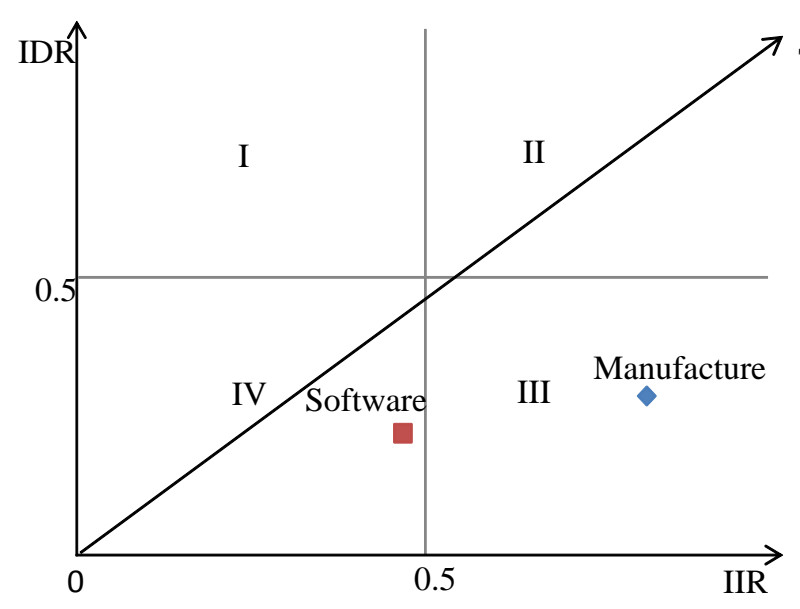

Fig. 1 Industrial Property Graphic

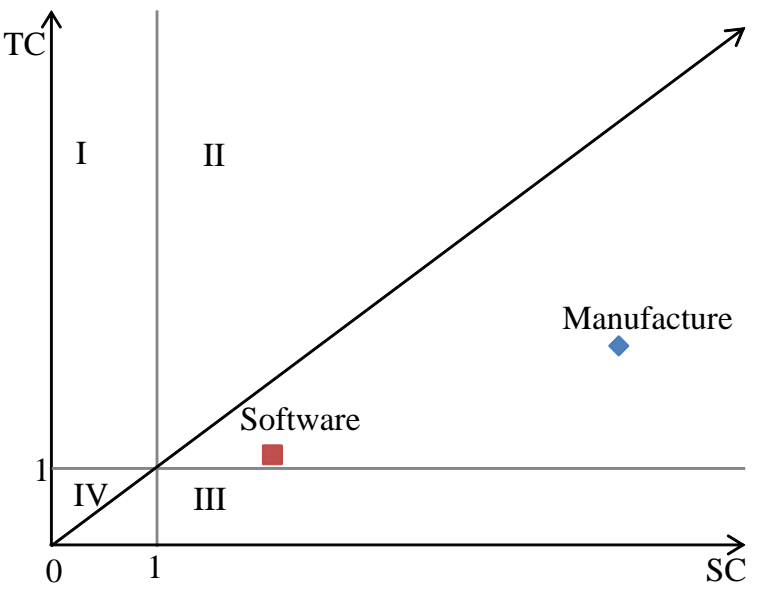

Fig. 2 Spread EFfect Graphic

Spread effect. Spread effect can be measured by the influence coefficient (TC) and the sensitivity coefficient (SC). The influence coefficient describes one sector's demand motive force to other sectors, and it's measured by the ratio of total intermediate inputs of one industry for one unit final production to the average total intermediate inputs of all industries. The sensitivity coefficient describes the change of one sector's production demand induced by one unit final production of other sectors. For the two coefficients, one is the average level of all sectors. The influence or induction power will rises with the growth of corresponding coefficient. The traditional arithmetic average brings bias in coefficient calculation for ignoring the differences of sectors' status in economy [10]. So we use the add value as a weight to make up it. The results show that information manufacture industry has the highest TC (5.40) and SC (2.57), TC (2.10) and SC (1.17) of the software industry are both more than the average of all industries.

We build an industry spread effect graphic based on Hirschman benchmark like the industrial property graphic. From Fig 2, information manufacture industry and software industry are both in the zone II. It means the two industries are both the intermediate industries that have strong radioactive and conditionality. They can play a more important role in the demand and supply of the upstream and downstream industries than the average level. They are the most sensitive industries of national economic development and should be the leading industries.

\section{Conclusions}

This paper attempted to estimate the economic impact of software industry in the process of IDII in China in method of IO analysis. The correlation effect analysis shows that there are differences of interrelationship of other manufacture industries between the software industry and information manufacture industry. the software industry has the high correlation of information manufacture industry both in consumption and supply, but the information manufacture industry has the higher correlation of other manufacture industries than software industry. We found that most of the production of the software industry isn't used to other manufacture industries but final consumption in industrial property analysis, and so did the information manufacture industry. The spread effect analysis indicates that both of the development of software industry and information manufacture industry has higher impact on other manufacture industries than the equal level of all industries. It's obvious that the information manufacture industry has higher contribution. We concluded that the software industry can play an important role in the process of IDII, but it's more indirectly relying on the development of information manufacture industry. 


\section{Acknowledgements}

Thanks for the financial support from National Social Science Fund (2011XGL0001), Soft Science Project of Science and Technology Plan of Sichuan (2012ZR0024), Humanities and Social Sciences Project of Education Department of Sichuan (14SB0508).

\section{References}

[1] L.Q. Liu and J.W. Feng, Evaluation and Empirical Analysis of China's Regional "Integration of Informationization and Industrialization”, Applied Mechanics and Materials 472 (2014): 971-984.

[2] Y.Z. XU and J. SUN, The Convergence of Information Industry and Manufacturing:An Analysis Based on Industry Performance, China Industrial Economics 7 (2009) 56-66 (In Chinese).

[3] J.G. LIU and Y.T. ZHAO, An Analysis of the Trend towards Servitization of Intermediate Inputs in Manufacturing Based on Input-Output Tables of some OECD Countries, Economy and Management, 9 (2006) 9-12 (In Chinese).

[4] L.Q. Cong, By developing Industry-oriented software to support realization of fusing informationization with industrialization, Information Technology and Standardization 5 (2012) 17-21 (In Chinese).

[5] Li, D.S., Analysis on the development of software industry and economic growth in China, Commercial Research 5 (2012) 95-100 (In Chinese).

[6] L.M. Xu, An Analysis on the Economic Effects of China's Information Industry Based on Input-output Model, Library and Information Service 12 (2010) 81-86 (In Chinese).

[7] R. F. Garbaccio, Price reform and structural change in the Chinese economy: policy simulations using a CGE model, China Economic Review 1 (1995) 1-34.

[8] W W. Leontief, Quantitative input and output relations in the economic systems of the United States, The review of economic statistics 3 (1936) 105-125.

[9] X. Tang, B.S. Zhang, L.Y. Feng, M. Masri, and A. Honarvar, Economic impacts and challenges of China’s petroleum industry: an input-output analysis, Energy 5 (2011) 2905-2911.

[10]Q.Y. Liu, Research on the input-output coefficients of structural analysis methods, Statistical Research 2 (2002) 40-42(In Chinese). 